\title{
Exploring the quantitative nature of empathy, systemising and autistic traits using factor mixture modelling
}

\author{
Rachel Grove, Andrew Baillie, Carrie Allison, Simon Baron-Cohen* and Rosa A. Hoekstra*
}

\section{Background}

Autism research has previously focused on either identifying a latent dimension or searching for subgroups. Research assessing the concurrently categorical and dimensional nature of autism is needed.

\section{Aims \\ To investigate the latent structure of autism and identify meaningful subgroups in a sample spanning the full spectrum of genetic vulnerability.}

\section{Method}

Factor mixture models were applied to data on empathy, systemising and autistic traits from individuals on the autism spectrum, parents and general population controls.

\section{Results}

A two-factor three-class model was identified, with two factors measuring empathy and systemising. Class one had high systemising and low empathy scores and primarily consisted of individuals with autism. Mainly comprising controls and parents, class three displayed high empathy scores and lower systemising scores, and class two showed balanced scores on both measures of systemising and empathy.

\section{Conclusions}

Autism is best understood as a dimensional construct, but meaningful subgroups can be identified based on empathy, systemising and autistic traits.

\section{Declaration of interest \\ None.}

\section{Copyright and usage}

(c) The Royal College of Psychiatrists 2015.
A central debate in the development of DSM $-5^{1}$ has been whether psychopathology is best conceptualised as a continuum of severity or as discrete categories of disorder, including the DSM-5 criteria for autism spectrum disorder. Understanding the latent structure of autism, also referred to as autism spectrum conditions (ASC), is important for guiding future conceptualisations of diagnostic criteria, as well as for informing the development of instruments assessing characteristics of ASC. A number of studies have assessed the latent structure of autism using either dimensional or discrete statistical techniques. ${ }^{2-6}$ In contrast to these methods, factor mixture modelling allows for the presence of a concurrently dimensional and categorical latent structure. ${ }^{7}$ Three papers have previously applied mixture modelling to assess the latent structure within children with a clinical ASC diagnosis and non-affected siblings. ${ }^{3,8,9}$ However, to date none of this work has focused on adult samples. Moreover, there is a large evidence base for the quantitative nature of autistic traits in the general population, ${ }^{10}$ with undiagnosed first-degree relatives of individuals with autism displaying intermediate (or subthreshold) levels of autistic traits, also termed the broader autism phenotype (BAP). ${ }^{11,12}$ It is therefore important to assess the latent structure of autism across the full range of genetic vulnerability, from low-risk general population samples to first-degree relatives (medium risk) and individuals with a clinical ASC diagnosis. The EmpathisingSystemising (E-S) theory of autism argues that the persistent deficits in communication and social interaction in autism can be accounted for by an impairment in empathy, particularly cognitive empathy (also referred to as 'theory of mind'), whereas the restricted or repetitive behaviours and unusually narrow interests can be explained by a strong drive to systemise. ${ }^{13}$ Previous research in the same sample as reported here suggested

*Joint senior authors. that empathy and systemising are discrete constructs that can reliably be measured in control samples, parents and individuals with ASC. ${ }^{14}$ The current study elaborates on these findings using mixture modelling methods. The study aims to assess the dimensional latent structure of empathy, systemising and autistic traits among individuals on the spectrum, first-degree relatives and the general population, while simultaneously examining whether meaningful subgroups can be identified.

\section{Method}

\section{Participants}

Individuals with autism, parents of a child with autism and general population controls were recruited via two volunteer webpages at the University of Cambridge (www.autismresearchcentre.com; www.cambridgepsychology.com). The total sample consisted of 1034 individuals (controls 232, parents 439, ASC group 363). Controls were restricted to individuals with no psychiatric history and consisted of 110 females and 122 males (mean age 33 years, s.d. =10). The parent group contained 298 females and 141 males (mean age 42 years, s.d. $=8$ ). Parents were included in the study if they had a child with a formal ASC diagnosis, but did not report having a diagnosis of autism themselves. The ASC group comprised 170 females and 193 males (mean age 36 years, s.d.=11). These individuals had received a formal clinical diagnosis of autism. The individuals in the parent and ASC groups were not part of the same family. IQ was assessed via an online adapted version of the Ravens Progressive Matrices. ${ }^{15}$ The control group scored significantly higher on the Ravens than both the parent group $(P<0.01)$ and individuals with ASC $(P<0.01)$. There were no differences in IQ between parents and individuals with autism $(P=0.11)$. As this study relied on self-report, the 
ASC group was restricted to high-functioning individuals, who were able to effectively complete these online questionnaires.

\section{Measures}

\section{Autistic traits}

The Autism Spectrum Quotient (AQ) ${ }^{16}$ is designed to assess quantitative autistic traits including those related to communication, social skills, attention to detail, imagination and attention switching. A total of 50 items are assessed with four response options: 'definitely agree', 'definitely disagree', 'slightly agree' and 'slightly disagree'. A raw scoring method was used, ${ }^{17}$ eliciting scores ranging from 50 to 200, higher scores indicating more autistic traits. Previous research suggested the AQ can be split into two reliable subscales relating to social and non-social traits. ${ }^{17}$ A broad social interaction factor (comprising 40 items assessing communication, social skills, imagination and attention switching) and an attention to detail factor (consisting of the remaining 10 items) were included in all analyses.

\section{Systemising}

The Systemising Quotient Revised (SQ $)^{18}$ is a measure designed to assess an individual's propensity to systemise; to construct and understand rule-based systems for categorisation. This measure includes 75 items scored on a Likert response scale with four response options: 'strongly agree', 'strongly disagree', 'slightly agree' and 'slightly disagree'. Strong responses score one point, with slightly agree/disagree responses receiving one point. Scores range from 0 to 150, with higher scores indicative of a heightened drive to systemise.

\section{Empathy}

The Empathy Quotient (EQ) ${ }^{19}$ is a self-report measure of empathy. This 40-item measure includes equivalent response options and scoring methods to the SQ. Full endorsement of all items gives a score of 80 , with higher scores indicative of a better capacity to empathise.

Apart from the AQ, SQ and EQ self-report questionnaires, which were included in the mixture analyses, data were also collected on two performance-based measures of empathy. Due to a large proportion of missing data in the sample of fathers these measures were not included in the factor analyses. The 'Reading the Mind in the Eyes Test' revised (Eyes) ${ }^{20}$ assesses how accurately an individual can read the emotion in another by viewing only the eye region of the face. A total of 36 items are presented with four descriptions of mental states. Relatively subtle and complex mental states are used, for example, joking, insisting, amused and relaxed, making the task an advanced test of empathy. The total number of correct items is recorded, with higher scores reflecting better ability.

The Karolinska Directed Emotional Faces $(\mathrm{KDEF})^{21}$ test is a test of more basic emotion recognition, including the basic emotions happy, sad, angry, afraid, disappointed, surprised and neutral, and giving participants the opportunity to view the whole face. This measure consists of 140 items in which accuracy and response time information is recorded. Response times were weighted for accuracy. ${ }^{22}$ For ease of interpretation, the KDEF was rescored so that higher values indicate higher ability rather than a slower response time.

\section{Analytic strategy}

\section{Confirmatory factor analysis}

Confirmatory factor analyses (CFA) were conducted to assess the dimensional structure of empathy, systemising and autistic traits using the EQ, SQ and the two subscales of the AQ. A one-factor model was implemented to assess whether these traits lie on a continuum of severity (Model 1). Next, a two-factor model representing the distinction between empathy and systemising was fit to the data (Model 2). The EQ and the social interaction factor of the AQ were predicted to load onto a factor representing empathy, with the SQ and the attention to detail factor of the AQ loading onto a second-factor representing systemising.

\section{Latent class analysis}

Latent class analysis (LCA) is a technique designed to evaluate whether a number of observed variables (in this case empathy, systemising and autistic traits) can help to define an underlying categorical variable or class. ${ }^{23}$ A series of models ranging from one to five classes were implemented (Models 3-7).

\section{Factor mixture models}

Factor mixture models (FMM) combining both CFA and LCA models were also assessed. Measurement invariance is given when a measurement model relating observed variables to underlying latent variables does not vary across latent classes. ${ }^{24}$ There is considerable debate over the invariance restrictions placed on classes in FMM and their varying effects on the results obtained. ${ }^{25}$ Lubke \& Muthén ${ }^{7}$ show that correct class assignment is maximised by constraining factor loadings to be equal across classes while allowing thresholds to vary. This method was therefore applied to all models in the current study. Models were estimated up to and including the number of factors from the best fitting CFA model and the number of classes from the best fitting LCA model (Models 8-17).

Analyses were estimated using Mplus version $7^{26}$ with the robust maximum likelihood ratio estimator. A number of fit indices were estimated including the Akaike information criterion (AIC), Bayesian information criterion (BIC), sample size adjusted BIC (SSABIC), entropy and the Lo-Mendell-Rubin likelihood ratio test (LMR). ${ }^{27}$ Lower AIC, BIC and SSABIC values are indicative of a better fit to the data. These fit statistics were used to evaluate the fit of the CFA models. In LCA and FMM, the BIC has been shown to be more reliable in obtaining the best fitting models than AIC and SSABIC. ${ }^{27,28}$ Therefore, the BIC was used to reach a final decision on the best fitting model in LCA and FFM analyses. In addition to these measures, the LMR test and entropy statistic are useful to determine the optimal number of latent classes. An LMR value that is not statistically significant indicates that a model with one less class provides a better fit to the data. ${ }^{29}$ Similarly, the entropy statistic is a measure of the accuracy with which each individual can be categorised into a latent class, with higher entropy values indicating better categorisation. ${ }^{30}$ In addition to AIC, BIC and SSABIC, the LMR and entropy statistic were also consulted when evaluating the LCA and FMM models.

As well as taking into account the fit indices mentioned above, in evaluating the model fit the conceptual appropriateness of the latent class profiles was also considered. Once the best fitting model was identified, further analyses assessing mean differences and demographic information for the classes identified was conducted using SPSS Version 21.0. ${ }^{31}$

\section{Results}

As reported previously, ${ }^{18,20,32}$ there were a number of differences in the mean scores on the questionnaires for controls, parents and individuals with ASC (Table 1). Individuals with ASC scored significantly lower on the social interaction items of the AQ and 


\begin{tabular}{|c|c|c|c|c|}
\hline & $\begin{array}{c}\text { AQ_Soc } \\
\text { Mean (s.d.) }\end{array}$ & $\begin{array}{c}\text { AQ_att } \\
\text { Mean (s.d.) }\end{array}$ & $\begin{array}{c}\text { SQ } \\
\text { Mean (s.d.) }\end{array}$ & $\begin{array}{c}\text { EQ } \\
\text { Mean (s.d.) }\end{array}$ \\
\hline Controls & $117.2(15.9)$ & $25.3(5.1)$ & 63.7 (23.9) & $43.1(14.2)$ \\
\hline Male & $113.4(15.3)$ & $25.1(5.0)$ & $67.0(23.0)$ & 38.5 (12.9) \\
\hline Female & $121.5(15.5)$ & $25.4(5.3)$ & $60.0(24.5)$ & 48.1 (13.9) \\
\hline Parents & $113.6(22.4)$ & $24.3(5.6)$ & $57.8(25.3)$ & 42.4 (18.2) \\
\hline Male & $107.0(23.2)$ & $24.7(5.4)$ & $71.0(26.9)$ & $33.2(17.1)$ \\
\hline Female & $116.7(21.3)$ & $24.1(5.7)$ & $51.6(22.0)$ & 46.8 (17.1) \\
\hline ASC & $75.2(16.5)$ & $29.9(5.1)$ & $77.4(25.2)$ & $18.4(10.0)$ \\
\hline Male & 77.7 (17.1) & $29.1(4.9)$ & $76.4(25.3)$ & $18.1(10.6)$ \\
\hline Female & $72.3(15.2)$ & $30.8(5.2)$ & 78.5 (25.2) & $18.7(9.4)$ \\
\hline
\end{tabular}

AQ_att, Attention to detail factor of the Autism Spectrum Quotient; AQ_Soc, Social interaction factor of the Autism Spectrum Quotient; ASC, autism spectrum condition; EQ, Empathy Quotient; SQ, Systemising Quotient Revised.

higher on the attention to detail items compared with controls and parents $(P<0.01)$. Individuals with ASC also obtained significantly higher SQ scores and lower EQ scores compared with all other participants. Parents scored significantly lower on the social interaction factor of the AQ than controls $(P<0.05)$. Control females displayed higher scores on the EQ and on the AQ social interaction factor as well as lower scores on the SQ than control males $(P<0.01)$. This pattern was also observed among parents $(P<0.01)$. Males with ASC displayed higher scores on the social interaction subscale of the AQ than females with ASC $(P<0.01)$, whereas females displayed higher scores on the attention to detail items of the AQ than males with autism $(P<0.05)$. However, there were no gender differences within the ASC group on the other two measures.

Model fit indices for the CFA, LCA and FMM analyses are given in Table 2. Results from the CFA indicated that a two-factor model (Model 2) consisting of empathy and systemising provided the best fit to the data, with lower AIC, BIC and SSABIC values than the one-factor model. There was a moderate negative correlation between the two factors, suggesting that better systemising is associated with lower empathy abilities. LCA models with up to five latent classes were then estimated. The LMR value for the five-class model did not reach significance, indicating that a model with one less class provided a better classification of individuals. The four-class LCA also had the smallest AIC, BIC and SSABIC values of the remaining four models (Model 6) as well as an entropy statistic of 0.81 . This model was therefore selected as providing the best fit to the data.

Mixture models consisting of one and two factors and up to five latent classes were then implemented. The smallest BIC values were identified in the two-factor three-class and two-factor fourclass models. The three-class model had the smallest BIC value as well as the largest entropy value and provided the most parsimonious explanation for the data. This model, designating three classes with varying levels of empathy, systemising and autistic traits, was therefore selected as the best fitting model

Table 2 CFA, LCA, and FMM results for empathy, systemising and autistic traits

\begin{tabular}{|c|c|c|c|c|c|c|}
\hline \multirow[b]{2}{*}{ Model } & \multirow{2}{*}{$\begin{array}{l}\text { Analysis/model } \\
\text { description }\end{array}$} & \multicolumn{5}{|c|}{ Fit statistics } \\
\hline & & AIC & $\mathrm{BIC}$ & SSABIC & Entropy & LMR \\
\hline \multicolumn{7}{|c|}{ CFA } \\
\hline 1 & $1 f$ & 33001.576 & 33060.870 & 33022.757 & & \\
\hline 2 & $\begin{array}{c}2 f \\
\text { Factor correlation }(-0.65)\end{array}$ & 32728.316 & 32787.610 & 32749.497 & & \\
\hline \multicolumn{7}{|c|}{ LCA } \\
\hline 3 & $1 \mathrm{C}$ & 35057.523 & 35097.053 & 35071.644 & & \\
\hline 4 & $2 C$ & 33498.692 & 33562.927 & 33521.638 & 0.872 & 0.0000 \\
\hline 5 & $3 c$ & 33012.493 & 33101.434 & 33044.264 & 0.852 & 0.0002 \\
\hline 6 & $4 C$ & 32814.899 & 32928.546 & 32855.495 & 0.812 & 0.0172 \\
\hline 7 & $5 c$ & 32717.575 & 32855.928 & 32766.997 & 0.800 & 0.2492 \\
\hline \multicolumn{7}{|c|}{ FMM } \\
\hline 8 & $1 \mathrm{f} 1 \mathrm{C}$ & 33001.576 & 33060.870 & 33022.757 & & \\
\hline 9 & $1 \mathrm{f} 2 \mathrm{C}$ & 32753.226 & 32842.168 & 32784.997 & 0.626 & 0.0000 \\
\hline 10 & $1 f 3 c$ & 32592.453 & 32711.041 & 32634.814 & 0.811 & 0.0563 \\
\hline 11 & $1 \mathrm{f} 4 \mathrm{C}$ & 32505.882 & 32654.118 & 32558.834 & 0.801 & 0.0822 \\
\hline 12 & $1 f 5 c$ & 32455.023 & 32632.905 & 32518.565 & 0.784 & 0.0003 \\
\hline 13 & $2 f 1 c$ & 32728.316 & 32787.610 & 32749.497 & & \\
\hline 14 & $2 f 2 c$ & 32578.082 & 32676.906 & 32613.383 & 0.769 & 0.0035 \\
\hline 15 & $2 f 3 c$ & 32491.851 & 32625.264 & 32539.508 & 0.760 & 0.0232 \\
\hline 16 & $2 f 4 c$ & 32462.540 & 32625.599 & 32520.787 & 0.707 & 0.0249 \\
\hline 17 & $2 f 5 c$ & 32443.404 & 32641.052 & 32514.007 & 0.726 & 0.0982 \\
\hline
\end{tabular}


(Model 15). Model fit statistics were compared across Models 2 (CFA), 6 (LCA) and 15 (FMM) to establish whether empathy, systemising and autistic traits are best conceptualised as dimensional, categorical, or a combination of both dimensional and categorical constructs. The mixture model (Model 15) provided the best fit across all three analyses and was therefore selected as providing the soundest explanation for the data.

Model 15 contained two factors representing empathy and systemising. This model identified three latent classes of individuals. Class one comprised $45 \%$ of the sample $(n=461$, mean age 38 years, s.d. $=11$ ), class two approximately $30 \%$ $(n=310$, mean age 37 years, s.d. $=11)$ and class three the remaining $25 \%(n=263$, mean age 40 years, s.d. $=9)$. Class three was significantly older than both class two $(P<0.01)$ and class one $(P<0.05)$. Class three also had a lower IQ score than class one $(P<0.05)$. The systemising and empathy factors were moderately correlated $(r=-0.49)$. There were no significant differences in the factor correlations across the three classes.

Mean differences on measures of empathy, systemising and autistic traits for each class are given in Fig. 1. Scores on all measures were converted to the same scale via $Z$ score transformation. These $Z$ scores were then increased by two to remove any negative values before being plotted to ease interpretation. The first class identified (Class S) scored significantly higher on self-reported systemising (including the SQ and the attention to detail factor of the AQ) and lower on self-reported empathy (including the $\mathrm{EQ}$ and the social interaction factor of the $\mathrm{AQ}$ ) than the other latent classes $(P<0.01)$. Class three (Class E) scored significantly higher on measures of empathy and lower on systemising than classes one and two $(P<0.01)$. Class two displayed scores on measures of systemising, empathy and autistic traits intermediate to that of the other two classes, showing a balance between empathy and systemising (Class B).

Subsequently, mean differences on performance-based measures of empathy were assessed. Class $\mathrm{S}$ scored significantly lower on the Eyes task than both Class B and Class E $(P<0.01)$. Class B also performed more poorly than Class $\mathrm{E}$ on this task (mean difference $-0.26, P<0.01$ ). Class $\mathrm{S}$ scored significantly lower than both other classes on the KDEF task $(P<0.01)$, with no differences in mean scores between Class B and Class E.

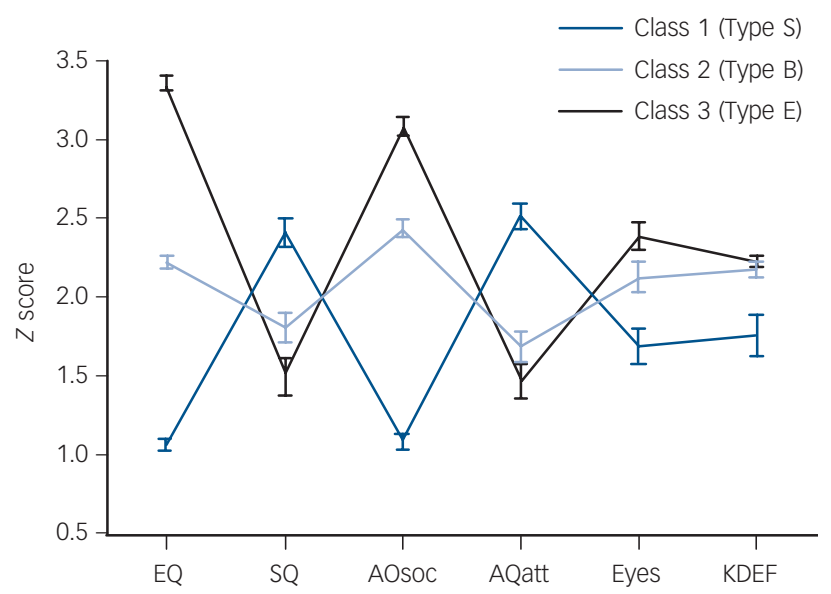

Fig. 1 Mean scores on self-report and performance tasks across classes.

AQatt, Attention to detail factor of the Autism Spectrum Quotient; AQsoc, Social interaction factor of the Autism Spectrum Quotient; EQ, Empathy quotient; Eyes, Reading the Mind in the Eyes task; KDEF, Karolinska Directed Emotional Faces task; $\mathrm{SQ}$, Systemising Quotient Revised.
The proportion of males, females, controls, parents and individuals with ASC falling into each class is given in Fig. 2. Class E primarily comprised females, whereas the gender division was similar in the other two classes. Individuals with ASC made up the majority of Class S (71\%), along with $23 \%$ of parents and a very small proportion of controls $(6 \%)$. Class B consisted of approximately $39 \%$ controls, $50 \%$ parents and $11 \%$ of individuals with ASC. Class E consisted predominantly of parents $(67 \%)$ and controls (32\%) with a very small proportion of those with ASC (1\%). Within the parent group, $38 \%$ of fathers compared with $18 \%$ of mothers fell into Class S. Half of the sample of mothers fell into Class E compared with $20 \%$ of fathers.

\section{Discussion}

Structural equation modelling including CFA, LCA and FMM analyses in a large sample of individuals with ASC, parents and controls indicated that the characteristics of autism, as measured in a sample spanning the full spectrum of genetic liability, are best described by a two-factor three-class mixture model. The quantitative nature of autistic traits is best captured by two moderately correlated latent factors representing systemising and empathy. In addition, three homogeneous latent classes of individuals could be identified by their mean scores on measures of empathy, systemising and autistic traits. Class one displayed superior performance on systemising, with significantly lower scores on both self-reported and performance-based tests of empathy (Class S). Class three demonstrated the opposite effect, showing increased scores on empathy tasks and lower performance on self-report measures of systemising (Class E). Class two appeared to be more balanced in terms of both empathy and systemising propensity (Class B).

The results provide support for the E-S theory, indicating that empathy and systemising are two separate constructs that together may partly provide a cognitive explanation of the characteristics of autism. The findings also lend indirect support to the current DSM-5 diagnostic criteria, including social and communication impairment (represented in the current study by difficulty with empathy) and repetitive behaviours and narrow interests (represented here by high systemising scores). EQ items map onto the social and communication domain assessing difficulties in social-emotional reciprocity, non-verbal communication and

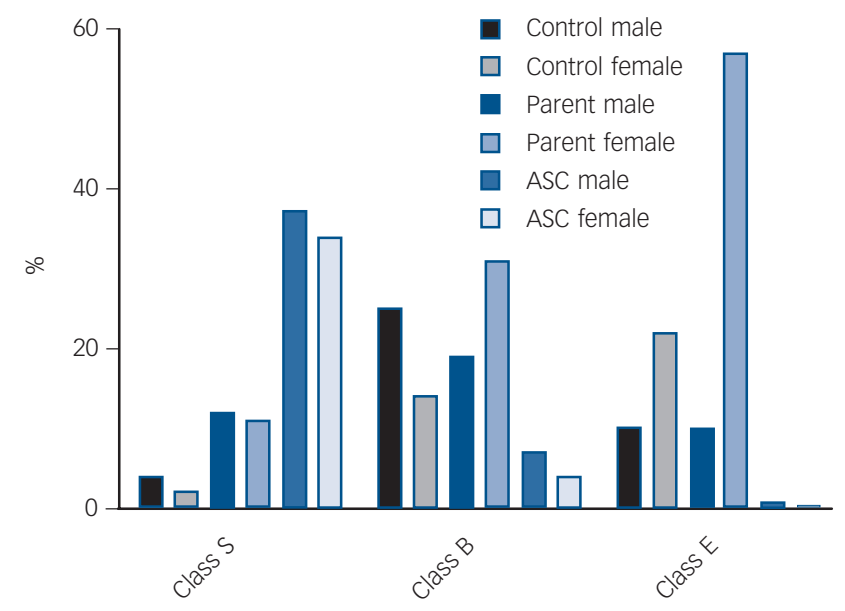

Fig. 2 Gender and group membership in each class.

ASC, autism spectrum condition. 
relationships. For example, 'I can easily tell if someone else wants to enter a conversation', 'I am quick to spot when someone in a group is feeling awkward or uncomfortable' and 'friendships and relationships are just too difficult, so I tend not to bother with them'. The restricted or repetitive behaviour or interests domain in DSM- 5 contains four criteria relating to stereotyped and repetitive movement or use of objects, insistence on sameness, fixated interests and hyper- or hyporeactivity to sensory stimuli. The first three of these DSM- 5 criteria may be (partly) accounted for by a drive to systemise. By engaging in stereotyped and repetitive actions, insisting on sameness and focusing on circumscribed interests, the world becomes more predictable and therefore easier to negotiate. It is as yet less clear how sensory reactivity relates to empathy and systemising. A recent study reported an association between sensory sensitivity and autistic traits, with greater sensitivity associated with more traits on the autism spectrum. ${ }^{33}$ However, further research is needed to comprehensively understand the association between sensory reactivity, empathy and systemising.

The two-factor structure found in the current study is consistent with previous factor analytic studies directly assessing autistic characteristics via diagnostic instruments, suggesting that the autism phenotype follows a dyadic structure comprising social communicative difficulties and non-social autistic traits. $3,5,14,34$ However, the two factors identified in the present study were moderately correlated $(r=-0.49)$, indicating that empathy and systemising are not entirely independent.

The E-S theory posits that there are five different cognitive profiles that can be identified based on empathy and systemising. Type E $(\mathrm{E}>\mathrm{S})$ are individuals with stronger empathy than systemising ability; Type $S(S>E)$ comprises individuals with systemising ability that is stronger than their empathy skills; Type $B(E=S)$ includes individuals with similar empathy and systemising ability; Extreme Type E (E $\gg S$ ) comprises individuals with above average empathy who have difficulty with systemising; and last, Extreme Type $S(S \gg E$ ) includes individuals with above-average systemising who have difficulty with empathy. ${ }^{13}$ Individuals with autism are thought to be represented by the Extreme Type S cognitive profile, with varying combinations of the other cognitive profiles in the general population. ${ }^{13}$ Using factor mixture modelling techniques, the current study identified classes that map very well onto the Type S, B and E profiles outlined in this theory.

Class $\mathrm{S}$ was characterised by low empathy and high systemising scores. It consisted predominantly of individuals with autism (both males and females), with only a very small proportion of the control sample falling into this class. The observation that the majority of individuals with ASC in this study (90\%) were identified within Class $\mathrm{S}$ follows the predictions of the E-S theory, with autism being characterised by an interest in systemising and difficulties with empathy. However, the finding that a small proportion of individuals with ASC also fell into the other two classes identified highlights the heterogeneity of autism: not every individual with ASC displays the Type S cognitive profile and shows superior systemising and impaired empathy. Approximately $20 \%$ of Class S comprised parents of a child with ASC, suggesting that these individuals display the BAP. Proportionally, more fathers than mothers fell into Class S ( $38 \% v$. 18\% respectively). This is consistent with previous research suggesting that the BAP is more common in male relatives. ${ }^{35}$ The presence of parents in Class S has clinical implications, as these parents may be especially well served by clinical advice and guidance provided in a systematic, factual manner. Parents who show difficulties with empathy themselves may also benefit from advice on how to manage and improve their own relationships with others.

A large proportion of parents, primarily mothers, were also represented in Class E, characterised by low systemising and high empathy scores. This finding highlights that, even though the BAP is common in parents of a child with ASC, certainly not all parents show these characteristics. Approximately half of the mothers and $20 \%$ of fathers did not display any characteristics of the BAP. The stronger representation of mothers than fathers in Class E further supports the notion of the BAP being more common in male than female relatives.

A small proportion of individuals with ASC (approximately $10 \%$ ) fell into Class B, represented by equivalent scores on empathy and systemising. It is surprising that a proportion of individuals with ASC would fall into this class. However, further analyses within this class suggested a number of important differences. These individuals with an ASC diagnosis displayed similar scores on the EQ and SQ as the rest of Class B, and therefore increased self-reported empathy, and decreased systemising abilities compared with the rest of the ASC sample. However, this subsample of individuals scored significantly lower on the social interaction items of the AQ (mean difference 12.1, $P<0.01$ ) and higher on the attention to detail items (mean difference 2.7, $P<0.01$ ) than the rest of Class B. They also scored lower on both performance-based measures of empathy (Eyes mean difference 2.3, $P<0.01$; KDEF mean difference 82.5, $P<0.01$ ), displaying equivalent scores to individuals in Class $S$ and the ASC sample. This indicates that although the self-report EQ and SQ scores suggest these individuals have equivalent empathy and systemising abilities, their scores on performancebased measures highlight a difficulty with empathy. Interestingly, the $10 \%$ of individuals with ASC who fell in Class B were also significantly younger and had a lower IQ score than the other individuals in this class. It could be that limited insight or understanding of their difficulties had an impact on scores on self-report measures, whereas their difficulties with empathy were picked up by the relatively poor performance on the KDEF and Eyes tasks. This highlights the importance of the use of performance-based measures in research and clinical practice as well as the potential impact of cognitive ability and age on self-report measures.

The current study identified homogeneous subgroups based on levels of empathy, systemising and autistic traits in a sample spanning the entire spectrum of vulnerability to autism, from general population controls to individuals with a clinical diagnosis. Most previous studies aiming to define phenotypic subgroups in autism included clinical samples only. These studies generally highlighted that distinct groups can be identified based on either the presence of an ASC diagnosis, ${ }^{3}$ or severity of symptoms. ${ }^{8,9}$ A recent study in a large sample of children with a DSM-IV diagnosis of pervasive developmental disorder identified six classes of individuals, including three groups displaying impairment on both social and non-social domains, as well as three classes with impairment on only one of the two symptom dimensions. ${ }^{36}$ One class comprised individuals displaying social and communication difficulties, but no restricted repetitive behaviours, suggesting that, if these individuals had been diagnosed using current DSM-5 criteria rather than the DSM-IV, the new DSM-5 diagnosis of Social Communication Disorder $(\mathrm{SCD})^{1}$ may have been appropriate. Our study, using a sample spanning from controls to individuals with autism, rather than a clinical sample only, did not identify a separate class characterised by low empathy and average systemising, a pattern that would perhaps be expected for individuals with SCD. Nevertheless it would be of interest to study empathy and systemising in individuals with SCD and explore any potential differences in these traits compared to individuals with autism.

The findings of this study should be interpreted in the light of some limitations. Although the gender ratio was balanced for the 
control and ASC groups, there was a larger proportion of mothers $(n=298)$ than fathers $(n=141)$ in the parent group. Future research would benefit from the inclusion of more fathers for comparison. Second, this study included similar numbers of males and females, which is different from the documented gender ratio for ASC diagnoses of approximately 4:1. ${ }^{37}$ This relative overrepresentation of female participants with ASC is potentially due to the volunteer bias of online recruitment, with females being more likely to volunteer for research participation than men. ${ }^{38,39}$ However, given that males and females with ASC were equally distributed over the different classes (Class S: males $=170$, females $=155$; Class B: males $=21$, females $=14$; Class E: males $=2$, females $=1$ ), it is unlikely that this had a significant impact on the analyses and results of the study.

Third, this study only included performance-based measures of empathy abilities; no performance-based measure of systemising was available to compare against the self-report questionnaire data. It should be stressed that as this study included self-rated measures, all individuals with ASC were high functioning. The results from this study can therefore not be generalised to individuals with ASC and intellectual disability. Given that the data were collected online, it was also not possible to verify diagnoses of autism. However, there is evidence to suggest that clinical diagnoses of ASC reported by online volunteers are generally reliable. ${ }^{40}$

In conclusion, this study assessed the quantitative nature of empathy, systemising and autistic traits among individuals on the spectrum, first-degree relatives and general population controls. Results highlighted a two-factor three-class model in which two dimensions based on systemising and empathy were identified. This provides indirect support for the new diagnostic criteria outlined in DSM-5, which follow a dyadic rather than a triadic structure and include a dimensional rather than a categorical approach. Three meaningful classes were defined based on mean scores on empathy, systemising and autistic traits. Taken together, these results support the quantitative approach to autistic traits and confirm that even with the use of quantitative measures, meaningful subgroups can be identified.

Rachel Grove, PhD, Andrew Baillie, PhD, Department of Psychology, Centre for Emotional Health, Macquarie University, Sydney, NSW, Australia; Carrie Allison, PhD, Department of Psychiatry, Autism Research Centre, Cambridge University, Cambridge, UK; Simon Baron-Cohen, PhD, Department of Psychiatry, Autism Research Centre, Cambridge University, Cambridge, UK and CLASS Clinic, Cambridgeshire and Peterborough NHS Foundation Trust, UK; Rosa A. Hoekstra, PhD, Department of Psychiatry, Autism Research Centre, Cambridge University, Cambridge, UK and Faculty of Science, The Open University, Milton Keynes, UK

Correspondence: Rachel Grove, Department of Psychology, Centre for Emotional Health, Macquarie University, Sydney, NSW 2109, Australia. Email: rachel.grove@mq.edu.au

First received 22 Jul 2014, final revision 7 Dec 2014, accepted 22 Jan 2015

\section{References}

1 American Psychiatric Association. Diagnostic and Statistical Manual of Mental Disorders, 5th Edition (DSM-5). APA, 2013.

2 Constantino JN, Gruber CP, Davis S, Hayes S, Passanante N, Przybeck T. The factor structure of autistic traits. J Child Psychol Psyc 2004; 45: 719-26.

3 Frazier TW, Youngstrom EA, Speer L, Embacher R, Law P, Constantino J. Validation of proposed DSM-5 criteria for Autism Spectrum Disorder. J Am Acad Child Adolesc Psychiatry 2012; 51: 28-40.

4 Ingram GD, Takahashi TN, Miles JH. Defining autism subgroups: a taxometric solution. J Autism Dev Disord 2008; 38: 950-60.

5 Mandy WPL, Charman T, Skuse DH. Testing the construct validity of proposed criteria for DSM-5 Autism Spectrum Disorder. J Am Acad Child Adolesc Psychiatry 2012; 51: 41-50.
6 Frazier TW, Youngstrom EA, Sinclair L, Kubu CS, Law P, Rezai A. Autism spectrum disorders as a qualitatively distinct category from typical behavior in a large, clinically ascertained sample. Assessment 2010; 17: 308-20.

7 Lubke GH, Muthén B. Investigating population heterogeneity with factor mixture models. Psychol Med 2005; 10: 21-39.

8 Georgiades S, Szatmari P, Boyle M, Hanna S, Duku E, Zwaigenbaum L, et al. Investigating phenotypic heterogeneity in children with autism spectrum disorder: a factor mixture modeling approach. J Child Psychol Psychiatry 2013; 54: 206-15.

9 Georgiades S, Boyle M, Szatmari P, Hanna S, Duku E, Zwaigenbaum L, et al. Modeling the phenotypic architecture of autism symptoms from time of diagnosis to age 6. J Autism Dev Disord 2014; 44: 3045-55.

10 Constantino JN. The quantitative nature of autistic social impairment. Pediatr Res 2011; 69: 55R-62R.

11 Sucksmith E, Roth I, Hoekstra RA. Autistic traits below the clinical threshold: re-examining the Broader Autism Phenotype in the 21st century. Neuropsychol Rev 2011; 21: 360-89.

12 Piven J, Palmer $\mathrm{P}$, Jacobi $\mathrm{D}$, Childress $\mathrm{D}$, Arndt S. Broader autism phenotype: evidence from a family history study of multiple-incidence autism families. Am J Psychiatry 1997; 154: 185-90.

13 Baron-Cohen S. Autism: the empathizing-systemizing (E-S) theory. Ann NY Acad Sci 2009; 1156: 68-80.

14 Grove R, Baillie A, Allison C, Baron-Cohen S, Hoekstra RA. Empathizing, systemizing, and autistic traits: latent structure in individuals with autism, their parents and general population controls. J Abnorm Psychol 2013; 122: 600-9.

15 Raven J, Raven JC, Court JH. Manual for Raven's Progressive Matrices and Vocabulary Scales. Section 1: General Overview. Harcourt Assessment, 2003.

16 Baron-Cohen S, Wheelwright S, Skinner R, Martin J, Clubley E. The AutismSpectrum Quotient (AQ): evidence from Asperger syndrome/high-functioning autism, males and females, scientists and mathematicians. J Autism Dev Disord 2001; 31: 5.

17 Hoekstra RA, Bartels M, Cath DC, Boomsma DI. Factor structure, reliability and criterion validity of the Autism-Spectrum Quotient (AQ): a study in Dutch population and patient groups. J Autism Dev Disord 2008; 38: 1555-66.

18 Wheelwright S, Baron-Cohen S, Goldenfeld N, Delaney J, Fine D, Smith R, et al. Predicting Autism Spectrum Quotient (AQ) from the Systemizing QuotientRevised (SQ-R) and Empathy Quotient (EQ). Brain Res 2006; 1079: 47-56.

19 Baron-Cohen S, Wheelwright S. The empathy quotient: an investigation of adults with Asperger syndrome or high functioning autism, and normal sex differences. J Autism Dev Disord 2004; 34: 163-75.

20 Baron-Cohen S, Wheelwright S, Hill J, Raste Y, Plumb I. The "Reading the mind in the eyes" Test revised version: a study with normal adults, and adults with Asperger syndrome or high-functioning autism. J Child Psychol Psychiatry 2001; 42: 241-51.

21 Lundqvist D, Flykt A, Öhman A. The Karolinska Directed Emotional Faces. Department of Clinical Neuroscience, Psychology section: Karolinska Institutet, 1998.

22 Sutherland A, Crewther DP. Magnocellular visual evoked potential delay with high autism spectrum quotient yields a neural mechanism for altered perception. Brain 2010; 133: 2089-97.

23 Hagenaars J, McCutcheon AL. Applied Latent Class Analysis. Cambridge University Press, 2002.

24 Meredith W. Measurement invariance, factor analysis and factorial invariance. Psychometrika 1993; 58: 525-43.

25 Lubke GH, Muthén, B. Performance of factor mixture models as a function of model size, covariate effects, and class-specific parameters. Struct Equ Modeling 2007; 14: 26-47.

26 Muthén B. Latent variable hybrids: overview of old and new models. In Advances in Latent Variable Mixture Models (eds GR Hancock, KM Samuelsen): 1-24. Information Age Publishing, 2008.

27 Nylund KL, Asparouhov T, Muthen BO. Deciding on the number of classes in Latent Class Analysis and Growth Mixture Modeling: a Monte Carlo simulation study. Struct Equ Modeling 2007; 14: 535-69.

28 Gebregziabher M, Shotwell MS, Charles JM, Nicholas JS. Comparison of methods for identifying phenotype subgroups using categorical features data with application to autism spectrum disorder. Comput Stat Data Anal 2012; 56: $114-25$.

29 Lo Y, Mendell NR, Rubin DB. Testing the number of components in a normal mixture. Biometrika 2001; 88: 767-78.

30 Ramaswany V, Desarbo WS, Reibstein DJ, Robinson WT. An empirical pooling approach for estimating marketing mix elasticities with PIMS data. Market SCi 1993; 12: 103-24.

31 IBM Corp. IBM SPSS Statistics for Windows. IBM Corp, 2012. 
32 Sucksmith E, Allison C, Baron-Cohen S, Chakrabarti B, Hoekstra RA. Empathy and emotion recognition in people with autism, first-degree relatives and controls. Neuropsychologia 2013; 51: 98-105.

33 Tavassoli T, Hoekstra RA, Baron-Cohen S. The Sensory Perception Quotient (SPQ): development and validation of a new sensory questionnaire for adults with and without autism. Mol Autism 2014; 5: 29.

34 Mandy W, Charman T, Puura K, Skuse D. Investigating the cross-cultural validity of DSM-5 autism spectrum disorder: evidence from Finnish and UK samples. Autism 2014; 18: 45-54.

35 Scheeren AM, Stauder JE. Broader autism phenotype in parents of autistic children: Reality or myth? J Autism Dev Disord 2008; 38: 276-87.

36 Greaves-Lord K, Eussen ML, Verhulst FC, Minderaa RB, Mandy W, Hudziak JJ, et al. Empirically based phenotypic profiles of children with pervasive developmental disorders: interpretation in the light of the DSM-5. J Autism Dev Disord 2013: 43: 1784-97.

37 Chakrabarti S, Fombonne E. Pervasive developmental disorders in pre-school children. JAMA 2001: 285: 3093-9.

38 Todd M, Davis KE, Cafferty TP. Who volunteers for adult development research? Research findings and practical steps to reach low volunteering groups. Int J Aging Hum Dev 1983; 18: 177-84.

39 Rosenthal R, Rosnow RL. The Volunteer Subject. John Wiley and Sons 1975.

40 Lee H, Marvin AR, Watson T, Piggot J, Law JK, Law PA. Accuracy of phenotyping of autistic children based on internet implemented parent report. Am J Med Genet 2010; 153: 1119-26. psychiatry in history

\section{How could it happen? The killing of people in mental hospitals in Germany under the Third Reich}

\section{Alistair Stewart}

About 70000 people resident in mental hospitals in Germany were killed by gassing between 1940 and 1941. The number matched a target which had been set previously. This dreadful crime both required, and was facilitated by, a certain bureaucratic procedure. This was described by SS Colonel Viktor Brack under questioning before the Nuremberg Military Court in 1946 (translated from the German by the author).

Q. Do you mean to say these people were gassed in the chambers without any kind of written order? Who signed it?

A. Well Hitler had signed it of course.

Q. Hitler certainly ordered the euthanasia programme, but he never signed an order that, say, Johann Schmidt should undergo euthanasia. Who wrote the order that these people in those particular hospitals should be sent into the gas chambers?

A. There wasn't one single order of that kind, rather it was a consequence or the result of tests and checks corresponding to the wish Hitler expressed in his order ... Johann Schmidt, if I can keep to this name, Johann Schmidt's questionnaire, which was filled out by the hospital doctor at his first hospital A, was sent in three copies to three different expert assessors. In this connection Bouhler had insisted that none of these three assessors should be one of the doctors treating this patient. After their assessment they sent their questionnaires back to No.4 Tiergartenstrasse. There, the assessments of these three doctors were transferred from their three questionnaires on to a fourth questionnaire, once again bearing the name Johann schmidt. The chief assessor then decided whether this Johann Schmidt should be transferred to an observation unit. If he decided he should be transferred to an observation unit, he notified the Ministry of the Interior. The Ministry of the Interior then arranged the transfer of Johann Schmidt from hospital A, where he belonged, into an observation unit. In this observation unit a doctor was tasked with observing these patients. If his observations agreed with the results of the assessments by these assessors and their chief assessor, then the doctor would declare this to No. 4 Tiergartenstrasse on a list, or in other cases the chief assessors would form their own opinion with the doctor while on a visit to his hospital, by examining each individual patient. Then the Ministry of the Interior provided the observation unit with all the details of those patients who were now to be transferred to the euthanasia unit, and to this euthanasia unit a photocopy was sent from No. 4 Tiergartenstrasse with the chief assessor's observation note attached, so that the euthanasia doctor had al the patient's documents to hand, because in the end it was for him alone to decide whether, on the basis of the available assessment documents, he would give this patient a merciful death or not.

Q. So it was he who gave the final order to carry out euthanasia, in respect of Johann Schmidt, or of any other mentally ill person.

A. No, he didn't give any order, rather he carried out the euthanasia.

The court material is cited in Die Toetung Geisteskranker in Deutschland (1948) by Alice Platen-Hallermund, who attended the trials as a young doctor. Her book still awaits an English translation. The current translation is imperfect, but it does not exaggerate the cynicism of the language. 